\title{
Learning analytics: current trends and innovative practices
}

\author{
Lap-Kei Lee ${ }^{1} \cdot$ Simon K. S. Cheung ${ }^{2}$ Lam-For Kwok ${ }^{3}$
}

Published online: 11 February 2020

(C) Beijing Normal University 2020

\section{Learning analytics}

In the past decade, "learning analytics" has become one of the fields of educational technology that receives growing attention from educational researchers and practitioners (Hui and Kwok 2019). There are no generally accepted definitions of learning analytics but the most widely referenced one was defined by the 1 st International Conference on Learning Analytics and Knowledge: "Learning analytics is the measurement, collection, analysis and reporting of data about learners and their contexts, for purposes of understanding and optimizing learning and the environments in which it occurs" (Long and Siemens 2011). It is expected that, from the traces left by students and teachers in teaching and learning, learning analytics can enhance understanding of learning behaviors (Wong and Chong 2018); provide useful suggestions for policymakers, instructors, and learners (Hwang et al. 2014); and help educational practitioners to improve teaching and learning effectiveness (Bienkowski et al. 2012).

Learning analytics involves the use of a broad range of data and techniques for analysis, which includes the development of metrics (such as predicators and indicators for various factors) to understand the current situation and measure teaching and learning effectiveness, the use of different educational technologies to visualize and interpret data and to prompt remedial actions, and the refinement of the metrics and derivation of interventions to shape the learning environment (Avella et al. 2016;

Lap-Kei Lee

lklee@ouhk.edu.hk

1 School of Science and Technology, The Open University of Hong Kong, Homantin, Kowloon, Hong Kong

2 The Open University of Hong Kong, Homantin, Kowloon, Hong Kong

3 City University of Hong Kong, Tat Chee Avenue, Kowloon, Hong Kong 
Baker and Siemens 2014; Wong 2017). Over the past decade, enabled by many technological innovations, the teaching and learning process has been undergoing a lot of revolutionary changes, not only on instructional design and delivery but also on student advising and assessment (Fu et al. 2019). Massive open online courses are a good example. There inevitably generates a vast amount of learning-related data. Along with the rapid development of Internet and mobile technologies, learning analytics make use of big data for analyzing the vast amount of data obtained from the teaching and learning process (Aldowah et al. 2019; Baker and Inventado 2014).

\section{The trend of learning analytics}

By searching for article-type studies from the SCOPUS database using the keyword "learning analytics" or "learning analytics," it was found that the number of publications has increased at a fast pace since 2011 (see Fig. 1), showing the rapid growth of techniques, methods and applications of learning analytics.

Figure 2 shows the number of studies on learning analytics for individual application domains. Learning analytics are closely related to educational technologies, techniques in Computer Science and Decision Science. Thus, the top application domain is Computer Science (3073) and there are over a hundred of studies in Decision Sciences (182). Figure 2 also shows that learning analytics has been applied to a variety of other subjects, e.g., Social Sciences (1818), Engineering (603), Mathematics (492), Psychology (156), Arts and Humanities (110), Nursing (57), Business, Management and Accounting (94), Medicine (65).

Figure 3 shows the number of studies on learning analytics published with different keywords whose count is larger than 92. These keywords showed that learning analytics tools are commonly used in e-learning in the context of online learning and blended learning (e.g., e-learning, online learning, MOOC). Researchers and education practitioners are interested in learning analytics from pedagogical aspects (e.g., curricula, self-regulated learning, learning processes) and from technological aspects (e.g., data mining techniques, data visualization techniques, learning management systems). Excluding the keywords that are very general such as learning analytics, students, education, teaching, the top ten keywords are E-learning (863), Learning Systems (644), Computer Aided Instruction (569), Data Mining (478),

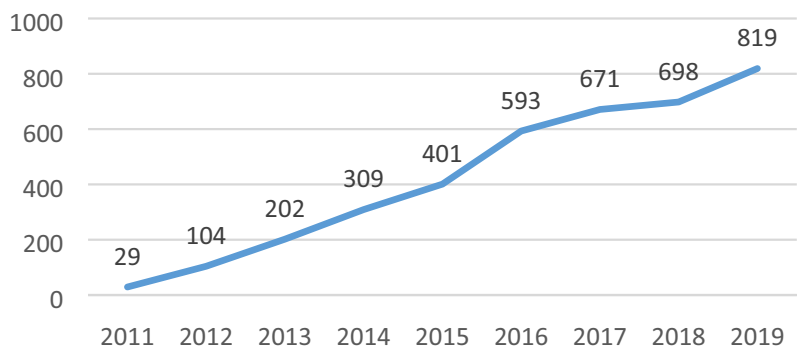

Fig. 1 Number of studies on learning analytics published in the SCOPUS database 


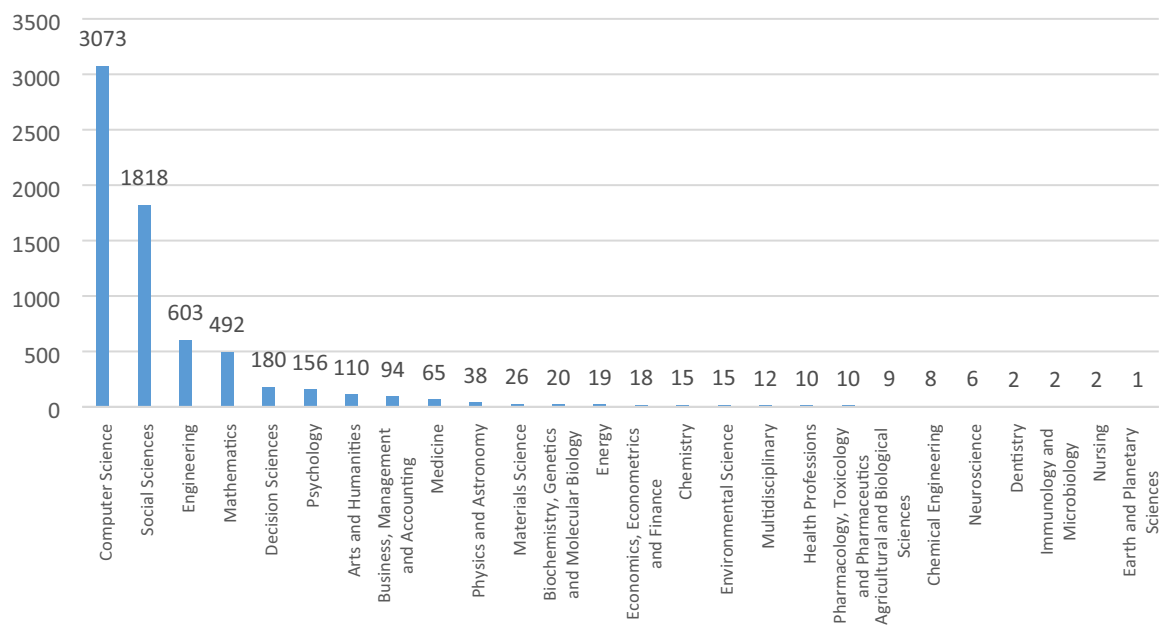

Fig. 2 Number of studies on learning analytics for individual application domains

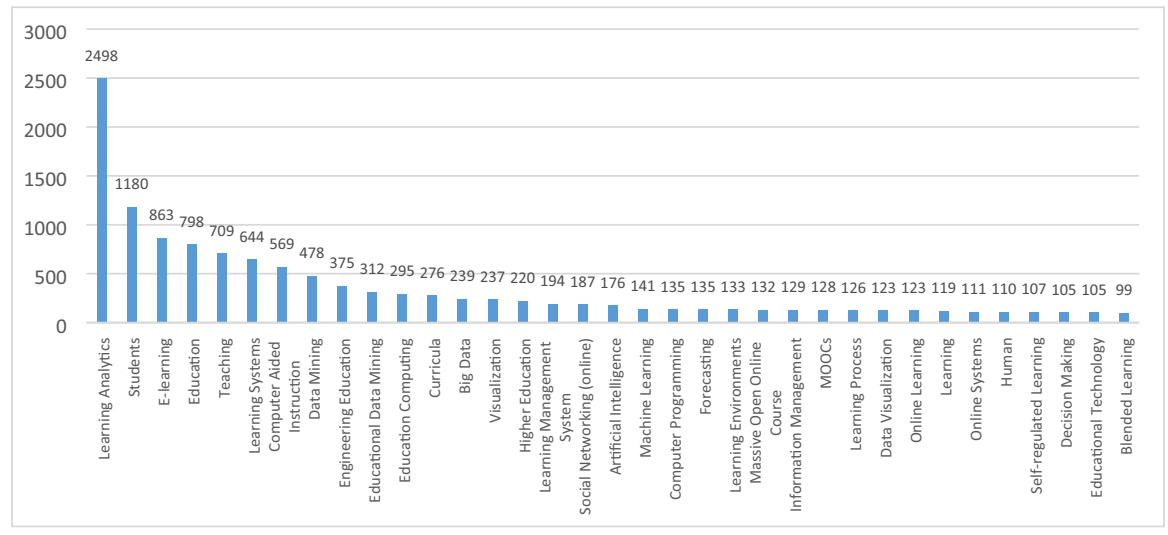

Fig. 3 Number of studies on learning analytics published with different keywords

Educational Data Mining (312), Curricula (276), Big Data (239), Visualization (237), Learning Management System (194), Social Networking (online) (187).

\section{Trends and innovative practices of learning analytics reported in this special issue}

Although the number of studies on learning analytics is increasing at a fast pace, researchers and education practitioners have reported various problems in designing learning analytics tools and applying learning analytics in teaching and learning (Wilson et al. 2017). For example, the design and implementation of learning analytics tools are largely driven by IT departments or learning analytics specialists, 
which is a challenge to many educators; the application of learning analytics is also costly in terms of time, experience, and money (West et al. 2016).

The purpose of this special issue is to explore new trends and innovative practices of learning analytics from both pedagogical and technological perspectives. A total of five articles appearing in this special issue are the extended and revised versions of selected papers from the 4th International Symposium on Educational Technology (ISET 2018) and the 11th International Conference on Blended Learning (ICBL 2018) held at the Kansai University, Osaka, Japan, during July 31, 2018 to August 2, 2018. ISET 2018 and ICBL 2018 were jointly organized by the Kansai University and the City University of Hong Kong, and co-organized by the Hong Kong Society for Multimedia and Image Computing, the Japan Society for Educational Technology, and the Japan Association for Educational Media Study.

The five articles present studies on learning analytics from pedagogical perspectives and technological perspectives, respectively, from elementary to higher education level.

The first article entitled "A review of learning analytics intervention in higher education (2011-2018)" focused on using learning analytics to deliver early intervention, which investigates those students who are likely to fail in their studies and provide them with just-in-time and personalized support. While intervention was claimed to be the biggest challenge in learning analytics, only few studies have addressed this issue. The article provides a meta-analysis of learning analytics intervention in higher education level during 2011 to 2018, and reviews 24 case studies. It identifies that most of these studies offer intervention as personalized recommendations and visualizations of learning data. These interventions mainly aim to increase students' study performance, offer personalized feedback and improve student retention. The article also identifies frequently used types of data for performing learning analytics intervention.

The second article entitled "Does group size influences middle school students' interaction in online forums?" studies how middle school students interacted with each other in online forums regulated by grouping and non-grouping strategies, where learning analytics are applied in the pedagogical perspective. Two cohorts of 40 students on a seven-day course participated in the online forum discussions with one divided into five groups and another without any grouping. From the student interaction data collected from the online forum, social network analysis and content analysis are adopted, respectively, to find out the structure and quality of students' interaction. This article shows that grouping does not affect the quality of individual posts, but leads to interesting and meaningful impact on students' interaction in the forums.

The third article entitled "How to facilitate self-regulated learning? A case study on open educational resources" focuses on students' Self-Regulated Learning (SRL), which includes setting the learning plan and goals, and then requires the students to regulate and evaluate the learning process independently. The article studies how SRL can be facilitated when traditional teacher-centered classroom teaching is replaced by blended learning using open educational resources on an online platform called i-Classroom at the elementary school level. The article applies learning analytics in the pedagogical perspective, and evaluates how the three aspects of SRL, 
namely learning motivation, learning management, and self-assessment, are affected according to different characteristics of the students. Strengths and weaknesses of the proposed methods are identified which provide insights for other researchers and education practitioners to promote students' SRL.

The fourth article entitled "College students' cognitive learning outcomes in flipped classroom instruction: a meta-analysis of the empirical literature" provides a meta-analysis of how flipped classroom instruction, a type of blended learning, affects college students' cognitive learning outcomes. It performs a moderator variable analysis to identify that the pedagogical approach was the only significant factor examined that affects the effectiveness of flipped classroom instruction. The article suggested that the flipped classroom instructional model helps college students to improve their cognitive learning and it is even more effective when instructors integrate individualized active and collaborative pedagogical approaches.

The fifth article entitled "Modified recommender system model for the utilized e-Learning platform" focuses on an innovative approach to content creation and a recommender system of learning material in college e-courses, which adopts learning analytics in the technical perspective. It presents the design of a recommender system model based on learners' ratings and content-based filtering, and shows how to enhance students' learning performance by suitable guiding in the e-learning platform, by students' involvement into the creation of study material and participation in the selection of the appropriate e-study material via students' instructor and system-generated ratings.

\section{Conclusion}

From the above-mentioned papers, it is evidenced that learning analytics can be applied to different stages of teaching and learning and in various settings, ranging from pedagogical to technological perspectives, and from elementary to higher education level. They identify some recent trends and innovative practices of learning analytics, which not only provides good indicators for education practitioners to adopt learning analytics but also inspires researchers to find valuable research directions.

Acknowledgements We would like to thank Prof. Ronghuai Huang, Prof. Gwo-Jen Hwang, Prof. SiuCheung Kong, Prof. Wenli Chen and Prof. Lanqin Zheng for their support to this Special Issue. Thanks also go to the reviewers who offered many constructive advices to help authors improve their papers.

\section{References}

Aldowah, H., Al-Samarraie, H., \& Fauzy, W. M. (2019). Educational data mining and learning analytics for 21st century higher education: A review and synthesis. Telematics and Informatics, 37, 13-49.

Avella, J. T., Kebritchi, M., Nunn, S., \& Kanai, T. (2016). Learning analytics methods, benefits, and challenges in higher education: A systematic literature review. Online Learning, 20(2), 13-29.

Baker, R., \& Siemens, G. (2014). Learning analytics and educational data mining. In: Keith-Sawyer R (ed) Cambridge handbook of the leaning sciences (2nd edn). Cambridge University Press: New York, NY, pp. 253-272. 
Baker, R. S., \& Inventado, P. S. (2014). Educational data mining and learning analytics. In J. A. Larusson \& B. White (Eds.), Learning analytics (pp. 61-75). Springer, New York, NY.

Bienkowski, M., Feng, M., \& Means, B. (2012). Enhancing teaching and learning through educational data mining and learning analytics: An issue brief. US Department of Education, Office of Educational Technology, 1, 1-57.

Fu, Q. K., Lin, C. J., \& Hwang, G. J. (2019). Research trends and applications of technology-supported peer assessment: A review of selected journal publications from 2007 to 2016. Journal of Computers in Education, 6(2), 191-213.

Hui, Y. K., \& Kwok, L. F. (2019). A review on learning analytics. International Journal of Innovation and Learning, 25(2), 197-222.

Hwang, G. J., Hung, P. H., Chen, N. S., \& Liu, G. Z. (2014). Mindtool-assisted in-field learning (MAIL): An advanced ubiquitous learning project in Taiwan. Educational Technology \& Society, 17(2), 4-16.

Long, P., \& Siemens, G. (2011). Penetrating the fog: Analytics in learning and education. EDUCAUSE Review, 46(5), 31-40.

West, D., Heath, D., \& Huijser, H. (2016). Let's talk learning analytics: A framework for implementation in relation to student retention. Journal of Asynchronous Learning Network, 20(2), 1-21.

Wilson, A., Watson, C., Thompson, T. L., Drew, V., \& Doyle, S. (2017). Learning analytics: Challenges and limitations. Teaching in Higher Education, 22(8), 991-1007.

Wong, A., \& Chong, S. (2018). Modelling adult learners' online engagement behaviour: Proxy measures and its application. Journal of Computers in Education, 5(4), 463-479.

Wong, B. T. M. (2017). Learning analytics in higher education: An analysis of case studies. Asian Association of Open Universities Journal, 12(1), 21-40.

Publisher's Note Springer Nature remains neutral with regard to jurisdictional claims in published maps and institutional affiliations.

Lap-Kei Lee is an Assistant Professor of the School of Science and Technology at the Open University of Hong Kong. He received his Bachelor's of Engineering in Computer Engineering and Doctor of Philosophy in Computer Science from the University of Hong Kong. His research interests include algorithms (especially in online job scheduling and data stream algorithms), algorithm engineering, educational technology and natural language processing.

Simon K. S. Cheung is the Director of IT in the Open University of Hong Kong, and the former Director of IT Services in the HKU School of Professional and Continuing Education. He received his BSc and $\mathrm{PhD}$ in Computer Science from the City University of Hong Kong, and Master of Public Administration from the University of Hong Kong. His research interests are in the areas of software engineering and IT in teaching and learning, where he has published 15 books, four journal special issues, and over 100 refereed journal articles, book chapters and conference papers.

Lam-For Kwok received his PhD in Information Security from the Queensland University of Technology. He is an Associate Professor in the Department of Computer Science and the Executive Director of CUBIC (CityU Business and Industrial Club) at the City University of Hong Kong. His research interests include information security and management, intrusion detection systems, and computers in education. He has extensive teaching and academic planning experience. He actively serves the academic and professional communities and has been acting as program chairs and organising chairs of international conferences, assessors and panel judges of various awards. 